\title{
Acne treatment patterns, expectations, and satisfaction among adult females of different races/ethnicities
}

This article was published in the following Dove Press journal:

Clinical, Cosmetic and Investigational Dermatology

2 May 2015

Number of times this article has been viewed

\section{Marta I Rendon' \\ David A Rodriguez ${ }^{2}$ \\ Ariane K Kawata ${ }^{3}$ \\ Arnold N Degboe ${ }^{4}$ \\ Teresa K Wilcox ${ }^{3}$ \\ Caroline T Burk ${ }^{5}$ \\ Selena R Daniels ${ }^{4}$ \\ Wendy E Roberts ${ }^{6}$}

'Rendon Center for Dermatology and Aesthetic Medicine, Boca Raton, FL, USA; ${ }^{2}$ Dermatology Associates and Research, Coral Gables, FL, USA; ${ }^{3}$ Evidera, Bethesda, MD, USA; ${ }^{4}$ Allergan Inc., Irvine, CA, USA; ${ }^{5}$ Health Outcomes Consultant, Laguna Beach, CA, USA; ${ }^{6}$ Generational and Cosmetic Dermatology, Rancho Mirage, CA, USA
Correspondence: Marta I Rendon Rendon Center for Dermatology and Aesthetic Medicine, 880 North West 13th Street, Suite 3C, Boca Raton,

FL 33486, USA

$\mathrm{Tel}+\mathrm{I} 56 \mid 5294667$

Fax +I 56I 7509873

Email martarendon@yahoo.com
Background: Limited data are available on acne treatment patterns, expectations, and satisfaction in the adult female subpopulation, particularly among different racial and ethnic groups.

Objective: Describe acne treatment patterns and expectations in adult females of different racial/ethnic groups and analyze and explore their potential effects on medication compliance and treatment satisfaction.

Methods: A cross-sectional, Web-based survey was administered to US females (25-45 years) with facial acne ( $\geq 25$ visible lesions). Data collected included sociodemographics, self-reported clinical characteristics, acne treatment use, and treatment expectations and satisfaction.

Results: Three hundred twelve subjects completed the survey (mean age, $35.3 \pm 5.9$ years), comprising black (30.8\%), Hispanic (17.6\%), Asian/other (17.3\%), and white (34.3\%). More than half of the subjects in each racial group recently used an acne treatment or procedure (black, 63.5\%; Hispanic, 54.5\%; Asian/other, 66.7\%; white, 66.4\%). Treatment use was predominantly over-the-counter (OTC) (47.4\%) versus prescription medications (16.6\%). OTC use was highest in white subjects (black, 42.7\%; Hispanic, 34.5\%; Asian/other, 44.4\%; white, 59.8\%; $P<0.05$ ). The most frequently used OTC treatments in all racial/ethnic groups were salicylic acid (SA) (34.3\%) and benzoyl peroxide (BP) (32.1\%). Overall, compliance with acne medications was highest in white versus black (57.0 \pm 32.4 vs $42.7 \pm 33.5$ days, $P>0.05$ ), Hispanic (57.0 \pm 32.4 vs

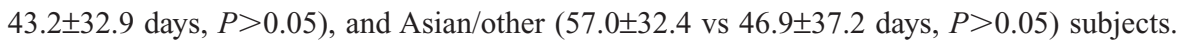
Most subjects expected OTC (73.7\%) and prescription (74.7\%) treatments to work quickly. Fewer than half of the subjects were satisfied with OTC treatment (BP, 47.0\%; SA, 43.0\%), often due to skin dryness (BP, 26.3\%; SA, 44.3\%) and flakiness (BP, 12.3\%; SA, 31.1\%). No statistically significant differences were observed among racial/ethnic groups in their level of satisfaction with OTC or prescription acne treatments.

Conclusion: Racial/ethnic differences were observed in acne treatment patterns in adult females, while treatment expectations were similar. Results indicate that treatment patterns and expectations may impact treatment satisfaction and medication compliance.

Keywords: acne, ethnicity, patient satisfaction, race, women

\section{Background}

Acne vulgaris (acne) is a common dermatologic condition. Although frequently associated with the adolescent population, the condition is also prevalent and persistent in adulthood. ${ }^{1}$

Available acne treatments include over-the-counter (OTC) and prescription (Rx) medications. The most common OTC and Rx medications are benzoyl peroxide (BP), salicylic acid (SA), antibiotics (topical/oral), and retinoids (topical). Although OTC acne medications are frequently used and widely available, there are limited clinical 
data supporting their efficacy. ${ }^{2}$ Treatment options are often individually tailored for each individual based on acne severity and other factors. Currently, there is no specific treatment for adult females or for different ethnic skin, creating a need for a standardized, evidence-based algorithm to manage adult female acne (AFA) in diverse skin types. ${ }^{3}$

In the absence of an AFA treatment paradigm, current treatment plans vary. However, patients still expect visible improvements shortly after treatment initiation, typically within 4-6 weeks. ${ }^{4}$ With unmet expectations, noncompliance with treatment regimens is common and may subsequently impact treatment efficacy due to nondaily use and suboptimal treatment durations. ${ }^{5}$

Evidence does indicate that treatment expectations may be linked to patient treatment satisfaction. ${ }^{6}$ However, treatment expectations may not consistently predict treatment outcomes, as psychological factors can also influence outcomes. $^{7}$

Previously, Callender et $\mathrm{al}^{8}$ conducted a study that evaluated acne treatment patterns, expectations, and satisfaction in white vs nonwhite females. However, the sample size limited between-group analyses for both race and ethnicity. The objectives of this large and ethnically diverse study were to: 1) describe and analyze acne treatment patterns and expectations in an extended cohort of adult females of different racial and ethnic backgrounds and 2) explore their potential effects on medication compliance and treatment satisfaction.

\section{Methods}

\section{Study design}

This cross-sectional, Web-based observational survey was conducted with subjects in the US between 2011 and 2013. The survey screened for subject-reported acne signs and captured data on sociodemographics, clinical characteristics, and acne treatment use. The study was approved by a central ethics review board prior to initiating contact with health panel members. Additional details on study methodology are described elsewhere. ${ }^{9}$

\section{Study population: recruitment and screening}

All subjects were recruited through the YouGov Panel (Palo Alto, CA, USA) using preregistered US Web panelists $\geq 18$ years of age. Data were collected in two waves: Cohort 1 (October-November 2011) and Cohort 2 (November 2013). Participants were required to be female, aged 25-45 years, with an active email address, with the ability to read and understand English, and have self-reported acne ( $\geq 25$ visible facial lesions). Enrollment targets were 200 subjects for Cohort 1 ( $\sim 25 \%$ black, $\sim 25 \%$ Hispanic and Asian/other, and $\sim 50 \%$ white) and 100 subjects for Cohort 2 ( $\sim 50 \%$ black, $\sim 25 \%$ Hispanic, and $\sim 25 \%$ Asian/other).

\section{Study variables}

Sociodemographics, clinical characteristics, acne treatment use, treatment expectations, and satisfaction data were collected. Treatment patterns included the type and frequency of use of acne, postinflammatory hyperpigmentation (PIH), and scar treatments within the last 3 months. OTC, Rx, and alternative (nonmedication) acne treatments used in the last 4 weeks were also collected. Treatment expectations were assessed by treatment onset of action and efficacy. Medication compliance was measured by the number of days of treatment use, and treatment satisfaction was assessed by treatment use in the last 4 weeks and recent acne clearing. Note that clinical terminology was not used in the survey. Lesions were referred to as pimples and defined as blemishes or bumps; PIH was referred to as "dark marks" and defined as skin discoloration from a healed lesion; scars were defined as raised or indented skin from a healed pimple.

\section{Statistical analyses}

Descriptive analyses were performed to summarize results in the pooled Cohorts 1 and 2 samples by racial/ethnic group (black, Hispanic, Asian/other, and white). For continuous variables, the sample size, mean, standard deviation (SD), median, minimum and maximum, and percent missing (where applicable based on survey design) were examined. For categorical variables, frequencies and percent missing were reported. Comparisons between racial/ethnic groups were conducted using the chi-square/Fisher's exact test and Student's $t$-test/analysis of variance (ANOVA) on clinical presentation, acne treatment use, expectations, medication compliance, and satisfaction variables.

\section{Results}

\section{Sample characteristics}

A total of 11,334 female panelists were invited to participate in the survey, of whom 4,894 responded to the email invitation, consented, and completed eligibility screening (Figure 1). After screening, 312 adult females with facial acne were eligible and completed the survey.

\section{Sociodemographic and clinical characteristics}

Sociodemographic characteristics of the sample are presented in Table 1. Subjects were predominantly white $(34.3 \%)$ or 


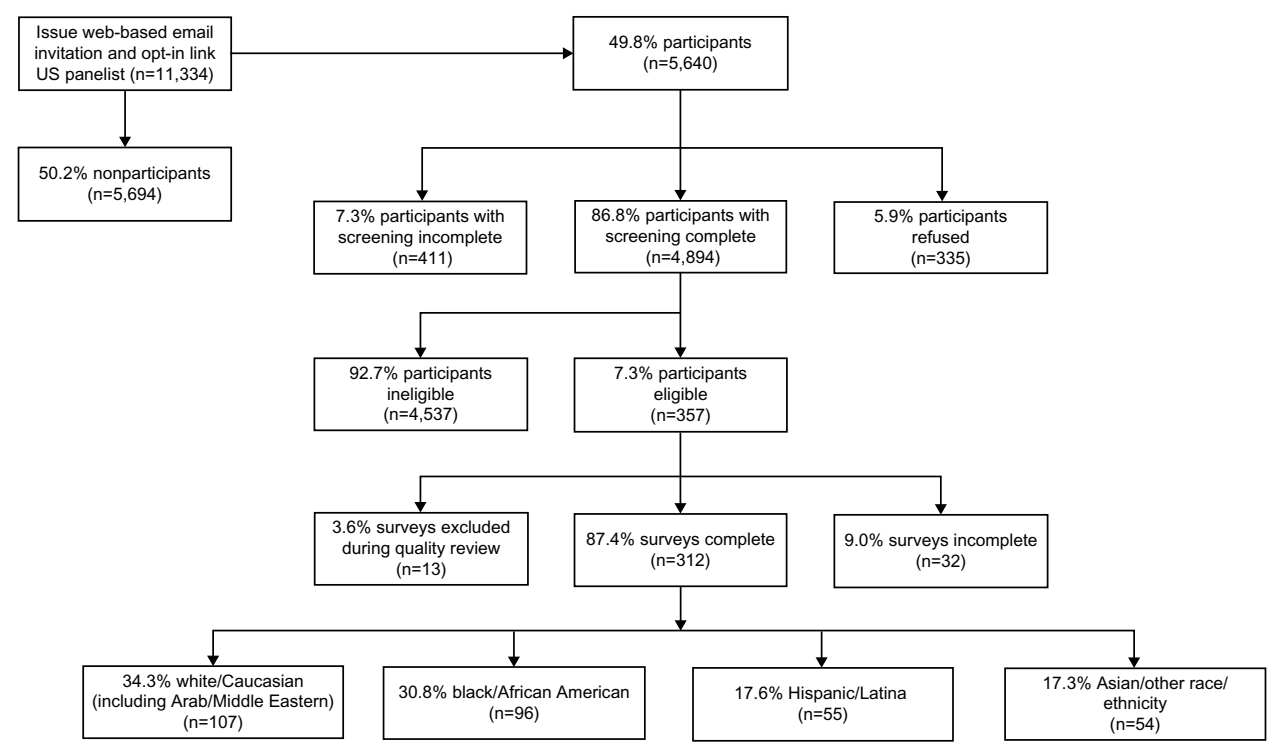

Figure I Acne cohorts I and 2 (total sample) survey participant disposition.

Note: Cohort I comprised subjects with data collected from October-November 20II, and Cohort 2 comprised subjects with data collected in November 2013.

black (30.8\%), with fewer Hispanic (17.6\%), and Asian/ other (17.3\%) participants. The average age was 35.3 years $(\mathrm{SD}, \pm 5.9)$ and more than half were employed full or part time $(51.0 \%)$. The only statistically significant difference observed between racial/ethnic groups in sociodemographic characteristics was in body mass index; fewer Asian/other subjects were overweight or obese compared with the other racial/ethnic groups $(P<0.05)$ (Table 1).

Subject-reported clinical and acne characteristics are summarized in Table 2.

\section{Acne treatment use}

In the past 3 months, more than half of subjects across all ethnic groups had used some type of acne treatment or procedure (total sample, 63.5\%; black, 63.5\%; Hispanic, 54.5\%; Asian/other, 66.7\%; white, 66.4\%). Among those, overall $42 \%$ (83/198) used behavioral or lifestyle changes and $32 \%(63 / 198)$ used homeopathic remedies. Black subjects reported recent use of PIH (referred to as "dark marks") and scar treatments more often than did other racial/ethnic groups (PIH: black, 40.6\%; Hispanic, 25.5\%; Asian/other, 27.8\%; white, $23.4 \%$; $P=0.07$; scar: black, $36.5 \%$; Hispanic, 20.0\%; Asian/other, 22.2\%; white, $15.9 \% ; P<0.05$ ). Among those who had used a PIH treatment, a higher proportion of black $(64.1 \%, 25 / 39)$ and Hispanic subjects $(78.6 \%, 11 / 14)$ reported using a skin-lightening agent in the last 3 months compared with Asian/other $(46.7 \%, 7 / 15)$ and white $(40.0 \%$, $10 / 25)$ subjects $(P=0.07)$.

Acne treatment use in the last 4 weeks was predominantly OTC medication across all racial/ethnic groups (47.4\%) versus Rx medications (16.7\%). OTC medication use was reported more by white subjects than by other groups (black, 42.7\%; Hispanic, 34.5\%; Asian/other, 44.4\%; white, 59.8\%; $P<0.05)$. No differences were observed in Rx medication use across racial/ethnic groups (black, 15.6\%; Hispanic, 14.5\%; Asian/other, 22.2\%; white, 15.9\%). SA (34.3\%), BP (32.1\%), and combinations of SA and BP (17.9\%) were the most commonly used OTC medications (Figure 2). Oral antibiotics (6.4\%), topical antibiotics (6.1\%), and topical retinoids $(5.8 \%)$ were the most commonly used Rx medications. No statistically significant differences were observed between $\mathrm{racial} / \mathrm{ethnic}$ groups in medication types (OTC/Rx).

\section{Treatment expectations}

Approximately three-fourths of the total sample and each racial/ ethnic group expected to see results from their medication overnight or in 1-2 weeks for both OTC (total sample, 73.7\%; black, 78.1\%; Hispanic, 70.9\%; Asian/other, 75.9\%; white, 70.1\%) and Rx (total sample, 74.7\%; black, 81.3\%; Hispanic, 76.4\%; Asian/other, 74.1\%; white, 68.2\%) acne treatments. Overnight results were expected by slightly more nonwhite than white subjects for OTC (total sample, 9.6\%; black, 11.5\%; Hispanic, 10.9\%; Asian/other, $16.7 \%$; white, $3.7 \% ; P=0.05$ ) and $\mathrm{Rx}$ (total sample, 12.5\%; black, 14.6\%; Hispanic, 12.7\%; Asian/other, 20.4\%; white, $6.5 \% ; P=0.07$ ) medications.

\section{Medication compliance}

In the past 3 months, white subjects reported using acne medications for a greater number of days compared with other racial/ethnic groups (black: $57.0 \pm 32.4$ vs $42.7 \pm 33.5$ days, $P>0.05$; Hispanic: $57.0 \pm 32.4$ vs $43.2 \pm 32.9$ days, $P>0.05$; Asian/other: $57.0 \pm 32.4$ vs $46.9 \pm 37.2$ days, $P>0.05$ ). 
Table I Sociodemographics by race/ethnicity

\begin{tabular}{|c|c|c|c|c|c|c|}
\hline \multirow[t]{2}{*}{ Parameter } & \multirow{2}{*}{$\begin{array}{l}\text { Total } \\
\text { sample } \\
(\mathbf{N}=3 \mid 2)\end{array}$} & \multicolumn{5}{|c|}{ Racial/ethnic group } \\
\hline & & $\begin{array}{l}\text { Black } \\
(n=96)\end{array}$ & $\begin{array}{l}\text { Hispanic } \\
(n=55)\end{array}$ & $\begin{array}{l}\text { Asian/other } \\
(n=54)\end{array}$ & $\begin{array}{l}\text { White } \\
(n=107)\end{array}$ & $P$-value ${ }^{a}$ \\
\hline Age, years & & & & & & 0.3324 \\
\hline Mean (SD) & $35.3(5.9)$ & $35.8(5.8)$ & $34.9(6.1)$ & $34.1(6.0)$ & $35.6(5.9)$ & \\
\hline Median (minimum-maximum) & $35.0(25-45)$ & $36.0(25-45)$ & $35.0(25-45)$ & $33.5(25-45)$ & $35.0(25-45)$ & \\
\hline Employment status, $\mathrm{n}(\%)$ & & & & & & 0.9380 \\
\hline Employed, full-time (paid) & $126(40.4)$ & $4 I(42.7)$ & $23(4 \mid .8)$ & $21(38.9)$ & $4 \mid(38.3)$ & \\
\hline Employed, part-time (paid) & $33(10.6)$ & $10(10.4)$ & $7(12.7)$ & $4(7.4)$ & $12(11.2)$ & \\
\hline Unemployed/disabled/retired/other & $|5|(48.4)$ & $43(44.8)$ & $25(45.5)$ & $29(53.7)$ & $54(50.5)$ & \\
\hline Prefer not to answer & $2(0.6)$ & $2(2.1)$ & $0(0)$ & $0(0)$ & $0(0)$ & \\
\hline Education, n (\%) & & & & & & 0.3380 \\
\hline Less than a high school diploma & II (3.5) & $4(4.2)$ & $2(3.6)$ & $\mathrm{I}(\mathrm{l} .9)$ & $4(3.7)$ & \\
\hline High school graduate & $55(17.6)$ & $19(19.8)$ & $13(23.6)$ & $4(7.4)$ & $19(17.8)$ & \\
\hline More than a high school diploma & $245(78.6)$ & $73(76.0)$ & $40(72.7)$ & $48(88.8)$ & $84(78.5)$ & \\
\hline Prefer not to answer & $\mathrm{I}(0.3)$ & $0(0)$ & $0(0)$ & I (I.9) & $0(0)$ & \\
\hline Total annual household income, $\mathrm{n}(\%)$ & & & & & & 0.2224 \\
\hline$\leq \$ 50,000$ & I $78(57.0)$ & $61(63.5)$ & $34(61.8)$ & $28(51.9)$ & $55(5 \mathrm{I} .4)$ & \\
\hline$>\$ 50,000$ & $125(40.1)$ & $31(32.3)$ & $21(38.2)$ & $24(44.4)$ & $49(45.8)$ & \\
\hline Prefer not to answer & $9(2.9)$ & $4(4.2)$ & $0(0)$ & $2(3.7)$ & $3(2.8)$ & \\
\hline Body mass index categories, $\mathrm{n}(\%)$ & & & & & & 0.0210 \\
\hline $\begin{array}{l}\text { Underweight (below I8.5)/normal } \\
(\text { (8.5-24.9) }\end{array}$ & $119(38.2)$ & $27(28.1)$ & I5 (27.2) & $30(55.6)$ & $47(43.9)$ & \\
\hline Overweight (25.0-29.9) & $63(20.2)$ & $22(22.9)$ & $14(25.5)$ & $8(14.8)$ & $19(17.8)$ & \\
\hline Obese (30.0 and above) & $94(30.1)$ & $35(36.5)$ & $16(29.1)$ & $10(18.5)$ & $33(30.8)$ & \\
\hline Missing & $36(11.5)$ & $12(12.5)$ & $10(18.2)$ & $6(11.1)$ & $8(7.5)$ & \\
\hline Insurance type, $n(\%)$ & & & & & & 0.3078 \\
\hline $\begin{array}{l}\text { Insurance coverage (provided by } \\
\text { employer, government, or private) }\end{array}$ & $246(78.8)$ & $78(8 \mid .2)$ & $42(76.4)$ & $38(70.4)$ & $88(82.2)$ & \\
\hline No insurance coverage & $66(21.2)$ & $18(18.8)$ & $13(23.6)$ & $16(29.6)$ & $19(17.8)$ & \\
\hline Prescription drug coverage, $\mathrm{n}(\%)$ & & & & & & 0.2468 \\
\hline No & $83(26.6)$ & $29(30.2)$ & $16(29.1)$ & $17(3 \mid .5)$ & $21(19.6)$ & \\
\hline Yes & $229(73.4)$ & $67(69.8)$ & $39(70.9)$ & $37(68.5)$ & $86(80.4)$ & \\
\hline
\end{tabular}

Note: analysis of variance (ANOVA; for continuous variables) or Pearson chi-square/Fisher's exact test (for categorical responses) by race group, with $P$-value based on comparison across white, black, Hispanic, and Asian/other groups.

\section{Treatment satisfaction}

In the past 4 weeks, OTC treatments containing BP and SA were the most frequently used; among subjects currently using an acne treatment, fewer than half "agreed" or "strongly agreed" that they were satisfied with their treatment (OTC BP, 47.0\% [47/100]; OTC SA, 43.0\% [46/107]; Table 3). The most frequently reported reasons for not being satisfied with $\mathrm{BP}$ or SA were skin dryness (BP, 26.3\%; SA, 44.3\%) and flakiness (BP, 12.3\%; SA, 31.1\%); bleaching of clothes or bedding with BP (8.8\%), and "cakey" makeup appearance with SA (19.7\%). Skin flakiness with SA occurred more frequently in Hispanic subjects $(83.3 \%, 5 / 6)$ compared with other racial/ethnic groups (black, 44.4\% [8/18]; Asian/other, $28.6 \%$ [2/8]; white, $13.3 \%$ [4/30]; $P<0.01$ ). Although only $16.7 \%$ of subjects had recently used an Rx acne treatment, more than half "agreed" or "strongly agreed" that they were satisfied with their treatment (Rx topical antibiotics, 78.9\% [15/19]; Rx topical BP, 73.3\% [11/15]; Rx topical retinoids,
$61.1 \%$ [11/18]; Rx oral antibiotics, 55.5\% [11/20]). No statistically significant differences were observed among racial/ethnic groups in their levels of satisfaction with OTC or Rx medications.

In the past 4 weeks, nearly two-thirds of subjects reported "minimal" to "no" clearing (total sample, 63.8\%; black, 55.2\%; Hispanic, 65.5\%; Asian/other, 64.7\%; white, 70.1\%). The amount of acne clearing achieved did not differ between racial/ethnic groups.

\section{Discussion}

This study builds on previous data ${ }^{8}$ by providing a robust sample size that enabled detailed between-group analyses of acne treatment patterns, expectations, medication compliance, and treatment satisfaction in diverse racial/ethnic groups. Findings from this survey confirm the varying impact of AFA among different races/ethnicities. Similar to results from the previous study, differences were observed 
Table 2 Clinical characteristics by race/ethnicity

\begin{tabular}{|c|c|c|c|c|c|c|}
\hline \multirow[t]{2}{*}{ Parameter, n (\%) } & \multirow{2}{*}{$\begin{array}{l}\text { Total } \\
\text { sample } \\
(\mathbf{N}=3 \mid 2)\end{array}$} & \multicolumn{5}{|c|}{ Racial/ethnic group } \\
\hline & & $\begin{array}{l}\text { Black } \\
(n=96)\end{array}$ & $\begin{array}{l}\text { Hispanic } \\
(n=55)\end{array}$ & $\begin{array}{l}\text { Asian/other } \\
(n=54)\end{array}$ & $\begin{array}{l}\text { White } \\
(n=107)\end{array}$ & $P$-value ${ }^{a}$ \\
\hline $\begin{array}{l}\text { What bothers or concerns you most about } \\
\text { your acne? }\end{array}$ & & & & & & $<0.0001$ \\
\hline Actual pimples & $40(12.8)$ & $2(2.1)$ & $6(10.9)$ & $4(7.4)$ & $28(26.2)$ & \\
\hline Dark marks (discolored skin) left by pimples & $31(9.9)$ & $18(18.8)$ & $6(10.9)$ & $4(7.4)$ & $3(2.8)$ & \\
\hline $\begin{array}{l}\text { Both pimples and dark marks } \\
\text { (discolored skin) }\end{array}$ & $207(66.3)$ & $63(65.6)$ & $34(61.8)$ & $42(77.8)$ & $68(63.6)$ & \\
\hline $\begin{array}{l}\text { Not applicable }- \text { I am no longer bothered } \\
\text { or concerned about my acne }\end{array}$ & $3(1.0)$ & $\mathrm{I}(\mathrm{I} .0)$ & $\mathrm{I}(\mathrm{I} .8)$ & $0(0.0)$ & I (0.9) & \\
\hline Not asked & 31 (9.9) & $12(12.5)$ & $8(14.5)$ & $4(7.4)$ & $7(6.5)$ & \\
\hline \multicolumn{7}{|l|}{ Facial acne location ${ }^{\mathrm{b}}$} \\
\hline Chin & $233(74.7)$ & $62(64.6)$ & $43(78.2)$ & $39(72.2)$ & 89 (83.2) & 0.0204 \\
\hline Cheeks & $253(81.1)$ & $81(84.4)$ & $46(83.6)$ & $46(85.2)$ & $80(74.8)$ & 0.2319 \\
\hline Forehead & $240(76.9)$ & $79(82.3)$ & 39 (70.9) & $41(75.9)$ & 81 (75.7) & 0.4236 \\
\hline Hairline & $139(44.6)$ & $31(32.3)$ & $23(4 I .8)$ & $28(51.9)$ & $57(53.3)$ & 0.0150 \\
\hline Jawline & $182(58.3)$ & $52(54.2)$ & $28(50.9)$ & $31(57.4)$ & $71(66.4)$ & 0.1882 \\
\hline Nose & I $43(45.8)$ & $34(35.4)$ & $27(49.1)$ & $25(46.3)$ & $57(53.3)$ & 0.0779 \\
\hline \multicolumn{7}{|l|}{$\begin{array}{l}\text { Where on your face do you most often } \\
\text { experience acne? }\end{array}$} \\
\hline Chin & $53(17.0)$ & $7(7.3)$ & $5(9.1)$ & II (20.4) & $30(28.0)$ & 0.0003 \\
\hline Cheeks & $148(47.4)$ & $54(56.3)$ & $34(61.8)$ & $27(50.0)$ & $33(30.8)$ & 0.0002 \\
\hline Forehead & $52(16.7)$ & $22(22.9)$ & $6(10.9)$ & $9(16.7)$ & $15(14.0)$ & 0.2251 \\
\hline Hairline & $7(2.2)$ & $2(2.1)$ & $\mathrm{I}(\mathrm{I} .8)$ & I (I.9) & $3(2.8)$ & 1.000 \\
\hline Jawline & $28(9.0)$ & $6(6.3)$ & $6(10.9)$ & $4(7.4)$ & $12(11.2)$ & 0.5957 \\
\hline Nose & $24(7.7)$ & $5(5.2)$ & $3(5.5)$ & $2(3.7)$ & $14(13.1)$ & 0.1131 \\
\hline Redness from facial acne in the past 4 weeks & & & & & & 0.0134 \\
\hline None/some & II4 (36.5) & 45 (46.9) & $21(38.2)$ & $21(38.9)$ & $27(25.2)$ & \\
\hline Moderate/a lot/extensive & $198(63.5)$ & $51(53.1)$ & $34(61.8)$ & $33(61.1)$ & $80(74.8)$ & \\
\hline Scarring from facial acne in the past 4 weeks & & & & & & 0.0373 \\
\hline None/some & II $4(36.5)$ & $29(30.2)$ & $22(40.0)$ & $14(25.9)$ & $49(45.8)$ & \\
\hline Moderate/a lot/extensive & $198(63.5)$ & $67(69.8)$ & $33(60.0)$ & $40(74.1)$ & $58(54.2)$ & \\
\hline Dark marks from facial acne in the past 4 weeks & & & & & & 0.0034 \\
\hline None/some & 120 & $27(28.1)$ & $22(40.0)$ & $16(29.6)$ & $55(51.4)$ & \\
\hline Moderate/a lot/extensive & $192(6 \mid .5)$ & 69 (71.9) & $33(60.0)$ & $38(70.4)$ & $52(48.6)$ & \\
\hline
\end{tabular}

Notes: analysis of variance (ANOVA) (for continuous variables) or Pearson chi-square/Fisher's exact test (for categorical responses) by race group, with $P$-value based on comparison across white, black, Hispanic, and Asian/other groups; 'subjects instructed to select all that apply; percentages may sum to more than I00\%.

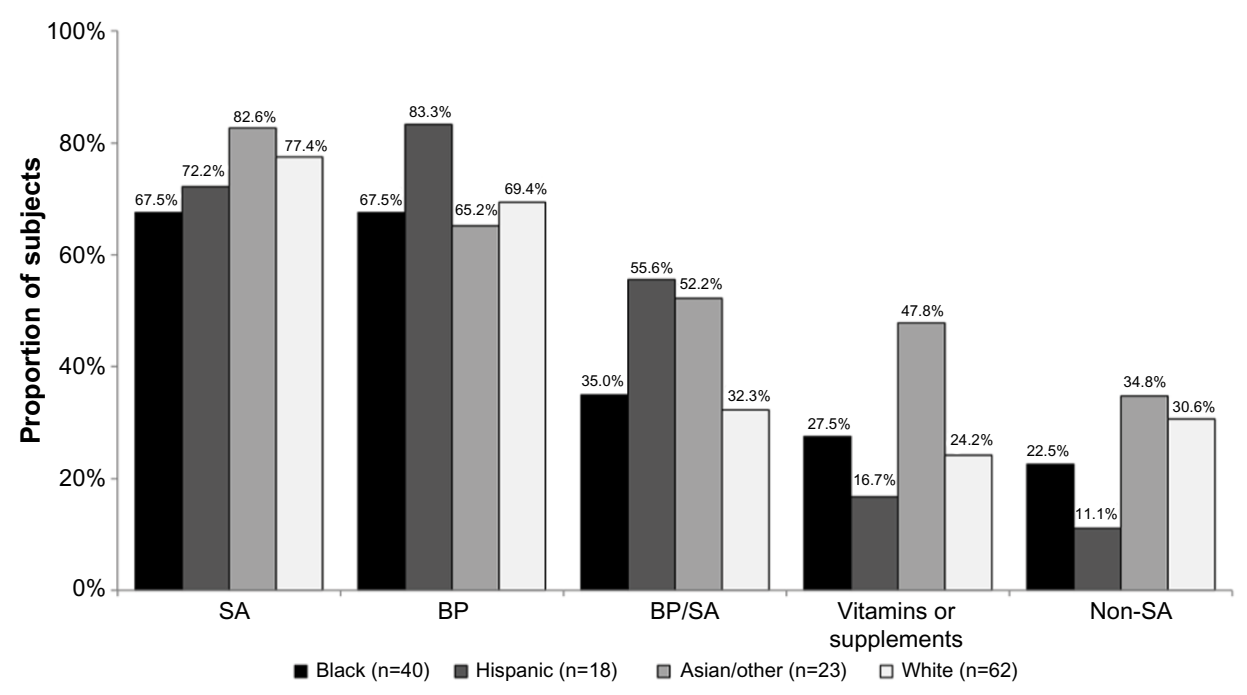

Figure 2 Over-the-counter topical medication use in the past 4 weeks (by race/ethnicity).

Abbreviations: BP, benzoyl peroxide; SA, salicylic acid. 
Table 3 Satisfaction with acne treatments by race/ethnicity

\begin{tabular}{|c|c|c|c|c|c|c|}
\hline \multirow{2}{*}{$\begin{array}{l}\text { Satisfied with acne medication used } \\
\text { in the past } 4 \text { weeks, } n(\%)\end{array}$} & \multirow{2}{*}{$\begin{array}{l}\text { Total } \\
\text { sample } \\
(\mathbf{N}=3 \mid 2)\end{array}$} & \multicolumn{5}{|c|}{ Racial/ethnic group } \\
\hline & & $\begin{array}{l}\text { Black } \\
(n=96)\end{array}$ & $\begin{array}{l}\text { Hispanic } \\
(n=55)\end{array}$ & $\begin{array}{l}\text { Asian/other } \\
(n=54)\end{array}$ & $\begin{array}{l}\text { White } \\
(n=107)\end{array}$ & $P$-value ${ }^{a}$ \\
\hline OTC products with benzoyl peroxide & & & & & & 0.8102 \\
\hline $\mathrm{n}$ & 100 & 27 & 15 & 15 & 43 & \\
\hline Strongly disagree/disagree/neutral & $53(53.0)$ & $13(48.1)$ & $7(46.7)$ & $8(53.3)$ & $25(58.1)$ & \\
\hline Agree/strongly agree & $47(47.0)$ & $14(5 \mid .9)$ & $8(53.3)$ & $7(46.7)$ & $18(4 \mid .9)$ & \\
\hline OTC products with salicylic acid & & & & & & 0.1475 \\
\hline $\mathrm{n}$ & 107 & 27 & 13 & 19 & 48 & \\
\hline Strongly disagree/disagree/neutral & $61(57.0)$ & $18(66.7)$ & $6(46.2)$ & $7(36.8)$ & $30(62.5)$ & \\
\hline Agree/strongly agree & $46(43.0)$ & $9(33.3)$ & $7(53.8)$ & $12(63.2)$ & $18(37.5)$ & \\
\hline OTC products with benzoyl peroxide and salicylic acid & & & & & & 0.9153 \\
\hline $\mathrm{n}$ & 56 & 14 & 10 & 12 & 20 & \\
\hline Strongly disagree/disagree/neutral & $26(46.4)$ & $7(50.0)$ & $4(40.0)$ & $5(4 I .6)$ & $10(50.0)$ & \\
\hline Agree/strongly agree & $30(53.6)$ & $7(50.0)$ & $6(60.0)$ & $7(58.4)$ & $10(50.0)$ & \\
\hline OTC products NOT containing salicylic acid & & & & & & 0.2690 \\
\hline $\mathrm{n}$ & 38 & 9 & 2 & 8 & 19 & \\
\hline Strongly disagree/disagree/neutral & $19(50.0)$ & $5(55.6)$ & $2(100.0)$ & $2(25.0)$ & $10(52.6)$ & \\
\hline Agree/strongly agree & $19(50.0)$ & $4(44.4)$ & $0(0.0)$ & $6(75.0)$ & $9(47.4)$ & \\
\hline
\end{tabular}

Notes: analysis of variance (ANOVA) (for continuous variables) or Pearson chi-square/Fisher's exact test (for categorical responses) by race group, with $P$-value based on comparison across white, black, Hispanic, and Asian/other groups.

Abbreviation: OTC, over-the-counter.

between groups in typical facial acne locations and acne signs.

Acne treatment patterns were not similar across different racial/ethnic groups. PIH and scar treatments were reportedly used more often by black subjects than by those of other races/ethnicities. This is consistent with the published literature, as the incidence of PIH is greater in a nonwhite population, more specifically in the black race. ${ }^{8,10}$ In addition, these findings support the consideration of race and ethnicity-related clinical characteristics when prescribing treatments for acne, such as focusing on treatments targeting PIH in ethnic skin. ${ }^{11}$

Acne treatment expectations were similar across the racial/ ethnic groups. All subjects expected quick resolution, with many expecting acne to clear overnight or within 2 weeks. These expectations of quick and visible improvements mirror findings from previous studies examining patient treatment expectations. ${ }^{4}$ In the authors' clinical experience, unmet expectations related to treatment efficacy and tolerability may impact medication compliance and subsequent outcomes. In this study, the majority of acne medications used across all racial/ethnic groups was OTC, which implies that the physician-patient interaction needed to set realistic treatment expectations was missing for most subjects.

Subject-reported medication compliance was not ideal, and daily use was rare by all racial/ethnic groups. Black, Hispanic, and Asian/other subjects reported using acne medications for fewer days than did white subjects. Acne medication compliance data for different races/ethnicities are limited; however, these findings are consistent with evidence indicating that black individuals with acne are less likely to adhere to the use of acne medications compared with white subjects with acne..$^{12}$ Strategies that may improve compliance include good physician-patient relationships, enhanced quality and quantity of office visits, patient education, and the use of fixeddose combination therapy, ${ }^{5,13}$ as well as access to physician care rather than OTC self-prescribed medications.

All subjects experienced limited success in clearing acne signs with their current acne treatment. This observation may be a result of medication noncompliance, but further exploration is needed to establish this association. An individual's satisfaction is strongly related to a lack of unmet expectations and the ability to consult with physicians on symptom cause and duration. ${ }^{6}$ Furthermore, satisfied patients have demonstrated that they are more likely to comply with treatment and take an active role in their own care. ${ }^{14}$

\section{Limitations}

Overall limitations for this survey have been described previously. ${ }^{9}$ Among those relevant to the current study, an individual's perception of acne signs and severity may differ from those in a clinical assessment made by a health care professional. Recall bias may exist in retrospective reports by subjects about specific acne treatments used and medication compliance. In addition, data on the resolution of acne were not collected, which may have impacted compliance data. Lastly, enrollment 
was limited to females who self-reported $\geq 25$ visible facial lesions, excluding those with milder cases and fewer lesions, thereby limiting the generalizability of the conclusions about treatment patterns and expectations to the overall adult female population with acne.

\section{Conclusion}

Racial/ethnic differences were observed in acne treatment patterns in adult females, while treatment expectations were similar. Based on study results, treatment patterns and expectations may potentially impact treatment satisfaction, treatment duration, and medication compliance. The findings from this study emphasize the diversity of acne signs and treatment patterns in AFA and help to characterize women with acne in different racial/ethnic groups. These findings may aid the clinical community in focusing on access to physician care and developing personalized treatment plans targeting patient needs that may improve compliance and optimize treatment outcomes.

\section{Acknowledgments}

The authors thank the following individuals for their contributions to the study: Andrew Alexis (Skin of Color Center at St Luke's-Roosevelt Hospital and Columbia University College of Physicians and Surgeons, New York, NY), Hilary E Baldwin (State University of New York Downstate Medical Center, Brooklyn, NY), Valerie D Callender (Callender Dermatology and Cosmetic Center, Glenn Dale, MD), Emil A Tanghetti (The Center for Dermatology and Laser Surgery, Sacramento, CA), Susan Taylor (Society Hill Dermatology, Philadelphia, PA), Joe Gorelick (California Skin Institute, San Jose, CA), and Tracee Douse-Dean (Lakeview Dermatology, Orland Park, IL) for their contributions to survey design; Karen Yeomans (UBC) for her contributions to survey design and execution; Krista A Payne (UBC) for survey design; Ren Yu (Evidera) for data analysis and statistical support; Marielle Bassel, Irene Pan, and Sunning Tao (UBC) for survey project support; Sepideh F Varon (Allergan Inc.) for strategy support in refocusing subject recruitment; Samantha Luks, Ashley Grosse, and Jason Cowden (YouGov) for Web survey management and implementation; and Owen Cooper (Evidera), Jiat-Ling Poon (Evidera), and Svetlana Pidasheva (Allergan, Inc.) for editorial support in the preparation and styling of this manuscript.

This study was sponsored by Allergan, Inc., Irvine, CA, USA. The sponsor and coauthors were involved in study design, statistical analysis, and interpretation of results. The authors had full access to the data and were involved in the critical review and revision of the manuscript. All authors provided approval prior to submission.

\section{Author contributions}

SRD and CTB participated in planning the study, collecting the data, and interpreting the results. AKK and TKW participated in planning the study, collecting the data, conducting the analyses, and interpreting the results. AND, DAR, MIR, and WER participated in interpreting the results. AKK and TKW drafted the manuscript, and all authors participated in the critical review and revision of the manuscript. All authors approved the final version of the manuscript for submission. All authors assume responsibility for the completeness and accuracy of the data and data analyses.

\section{Disclosure}

CTB serves as a consultant for Allergan Inc. AND and SRD were employees of Allergan, Inc. at the time this research was conducted. AKK and TKW are employees of Evidera. DAR has received honoraria, has consultancy agreements with, and has served as a speaker for Genentech, Merz, Leo Pharma, and Allergan, Inc. MIR has received honoraria from Allergan, Inc., Galderma, L'Oreal, Mary Kay, Merz, Pierre Fabre, and Valeant; has consultancy agreements with Allergan, Inc., L'Oreal, Mary Kay, MelaFind, Merz, and Pierre Fabre; has served as a speaker for Allergan, Galderma, and Merz; and has received research grants from Allergan, Inc., Amgen, Galderma, Leo Pharma, and Merck. WER has received honoraria from Allergan, Inc., Kythera, L'Oreal, MelaScience, Neostrata, SkinMedica, and Valeant; has consultancy agreements with Allergan, Inc., Kythera, L'Oreal, MelaScience, Neostrata, SkinMedica, Valeant, Top MD, and Theraplex; has served as a speaker for La Roche-Posay, Neostrata, and SkinMedica; and has received research grants from Allergan, Inc. The authors report no other conflicts of interest in this work.

\section{References}

1. Bhate K, Williams JC. Epidemiology of acne vulgaris. Br J Dermatol. 2013;168:474-485.

2. Decker A, Graber EM. Over-the-counter acne treatments: a review. J Clin Aesthet Dermatol. 2012;5:32-40.

3. Dreno B, Layton A, Zouboulis CC, et al. Adult female acne: a new paradigm. J Eur Acad Dermatol Venereol. 2013;27:1063-1070.

4. McEvoy B, Nydegger R, Williams G. Factors related to patient compliance in the treatment of acne vulgaris. Int J Derm. 2003;42:274-280.

5. Baldwin HE. Tricks for improving compliance with acne therapy. Derm Ther. 2006;19:224-236.

6. Jackson JL, Chamberlin J, Kroenke K. Predictors of patient satisfaction. Soc Sci Med. 2001;52(4):609-620. 
7. Haanstra TM, van den Berg T, Ostelo RW, et al. Systematic review: do patient expectations influence treatment outcomes in total knee and total hip arthroplasty. Health Qual Life Outcomes. 2012;10:152.

8. Callender VD, Alexis AF, Daniels SR, et al. Racial differences in clinical characteristics, perceptions and behaviors, and psychosocial impact of adult female acne. J Clin Aesthet Dermatol. 2014;7(7):19-31.

9. TanghettiEA, KawataAK, Daniels SR, Yeomans K, Burk CT, CallenderVD. Understanding the burden of adult female acne. J Clin Aesthet Dermatol. 2014; 7:22-30.

10. Perkins AC, Cheng CE, Hillebrand GG, Miyamoto K, Kimball AB. Comparison of the epidemiology of acne vulgaris among Caucasian, Asian, Continental Indian and African American women. J Eur Acad Dermatol Venereol. 2011;25:1054-1060.
11. Shah SK, Alexis AF. Acne in skin of color: practical approaches to treatment. J Dermatol Treat. 2010;21:206-211.

12. Tan X, Al-Dabagh A, Davis SA, et al. Medication adherence, healthcare costs and utilization associated with acne drugs in Medicaid enrollees with acne vulgaris. Am J Clin Dermatol. 2013;14(3):243-251.

13. Tan X, Feldman SR, Chang J, Balkrishnan R. Topical drug delivery systems in dermatology: a review of patient adherence issues. Expert Opin Drug Deliv. 2012;9(10):1263-1271.

14. Asadi-Lari M, Tamburini M, Gray D. Patients' needs, satisfaction, and health related quality of life: towards a comprehensive model. Health Qual Life Outcomes. 2004;2:32.

\section{Publish your work in this journal}

Clinical, Cosmetic and Investigational Dermatology is an international, peer-reviewed, open access, online journal that focuses on the latest clinical and experimental research in all aspects of skin disease and cosmetic interventions. All areas of dermatology will be covered; contributions will be welcomed from all clinicians and basic science researchers globally. This journal is indexed on CAS The manuscript management system is completely online and includes a very quick and fair peer-review system, which is all easy to use. Visit http://www.dovepress.com/testimonials.php to read real quotes from published authors.

Submit your manuscript here: http://www.dovepress.com/clinical-cosmetic-and-investigational-dermatology-journal 